\title{
Analysis of Dynamics in Hospital Admissions Due to Poisonings by Nonopioid Analgesics, Antipyretics and Antirheumatics (T39 ICD-10) in Lower Silesia Region of Poland in Years 2006-2012
}

\author{
Jaroslaw Drobnik ${ }^{1}$, Grzegorz Odonicz-Czarnecki ${ }^{2}$, Robert Suslo ${ }^{1}$ \\ ${ }^{1}$ Public Health Department, University Clinical Hospital in Wroclaw, Poland \\ ${ }^{2}$ Orthopedics and Musculoskeletal Traumatology Clinics, Wroclaw, Poland \\ robertsuslo@gmail.com
}

\begin{abstract}
Over-the-counter (OTC) medications and dietary supplements became popular in Poland in the last decades and also yearly amounts of acetaminophen poisonings, especially among children, rose in the recent years. Data on hospital admissions secondary to poisonings by nonopioid analgesics, antipyretics and antirheumatics (T39-T39.9 according to ICD-10) in the years 2006-2012, made available due to courtesy of the public healthcare insurance provider Narodowy Fundusz Zdrowia in Lower Silesia region of Poland (NFZ), were analyzed in order to find out the current incidence and trends in the most common and important poisonings to facilitate the process of diagnostics for both clinical and forensic medicine purposes. The study revealed that cases of poisoning by nonopioid analgesics, antipyretics and antirheumatics needing hospital admission were not very common in the analyzed time period, but some of them demonstrated a rising trend both the cases that were reported specifically as cases of confirmed poisoning by 4-aminophenol derivates and nonsteroideal anti-inflammatory drugs (NSAID) and those without any further specification (T39.1, T39.3 and T39 according to ICD-10, respectively). As under the current Polish legal regulations many of those drugs are sold as OTC medications they are commonly used in self-medication, especially as painkillers and antipyretics. OTC drugs are advertised in the mass-media as both safe and cheap, and are easily available to anyone in practically unlimited amounts and under different product names. As it causes elevated unintentional overdose risk as well as growing popularity of those drugs as tools in self-harm attempts possible intoxication with those drugs shall be seriously considered in differential diagnosis by every physician, including intensive care and anesthesiology medical staff.
\end{abstract}

Keywords: intoxication; analgesics; antipyretics; antirheumatics; over the counter drugs.

Abbreviations: NFZ - Narodowy Fundusz Zdrowia in Lower Silesia region of Poland, District Division in Wroclaw, OTC - over-the-counter drugs, NSAID - nonsteroideal anti-inflammatory drugs.

\section{INTRODUCTION}

In Poland the over-the-counter (OTC) medications and dietary supplements became popular in the last decades [1]. Almost 90\% of households in Poland acquire medical drugs without prescription of a physician - in the most cases this way are bought painkillers and non-steroid-anti-inflammatory drugs [2]. Since the political and economical transformation in the 1990s the OTC drugs sales in Poland grew at a constant rate that was as high as by $3 \%$ yearly [3]. The average Pole's expenses on medications also rose rapidly: in the year 2009 they were 6 times as big as in the year 1995 [4]. OTC medications marketing in various communication media, especially on television, is often aggressive and has significant impact on purchasing decisions [5]. There are several legal restrictions imposed on the conduct of medical products advertising in Poland; they include obligatory putting warnings into visual and audiovisual advertisements [6]. The information passed to television viewers is rarely adequate - but at the same time it shapes their needs in the way that contributes to the observed increased consumption of OTC medications [3]. Spreading the use of OTC drugs is often considered as one of the cornerstones of raising patients' independency in relation to medical staff that includes: self-treatment, self-medication and self-care. On the other hand, it causes many problems - including: masking serious health problems by temporarily alleviating their symptoms; polypragmasy side effects and occasional poisonings by OTC drugs [6]. Self-medication with OTC drugs is particularly popular among patients suffering from chronic pain-related conditions - in a 
significant part because of physicians' reservations that concern early introducing opioids into treatment, despite encouragements that exist in the current Polish pain management standards [7]. There is an important place reserved for every physician, especially for family doctors, in the system providing to patients information on risks associated with medications use, including OTC drugs [8]. It is especially true in case of drugs that may have side-effects to pregnant women or impair psychomotoric skills needed behind driving wheel or at workplace [9]. Most patients are willing to receive from their physicians additional information on the OTC drugs they use or intend to use [10]. The OTC medications are commonly considered as safe to patients and consequently big amounts of nonopioid analgesics and antipyretics are dispensed without physicians' prescription - in pharmacies or even literally everywhere: at regular stores, fuel stations, or even press kiosks. Although poisonings by those OTC drugs pose a serious clinical problem for toxicologists, medical intensive care and anesthesiology specialists as well as for forensic medicine and public health specialists, those OTC drugs are sold to virtually anyone, without any quantity limits, in many different configurations and under different names; it is true especially in case of acetaminophen-based medications [11]. Yearly amounts of acetaminophen poisonings among children, especially among girls, rose systematically in Poland over the recent years - with more than $2 / 3$ of them being intentional and nearly $1 / 3$ accidental; and with only rare cases of actual overdose [12]. The OTC drugs chronic toxicity, or even acute poisoning by these drugs, tend to be overseen, or even ignored, by medical staff as potential cause of the patients health problems [13]. Often, especially in cases of chronic intoxications, information derived from medical files is of crucial importance to the physician's ability to establish the proper diagnosis [14]. Preliminary differential diagnosis of most common medical drugs intoxication, while they cause the most typical symptoms, seems to be easy - but in fact clinical manifestations may be often misleading which causes serious delays in establishing the proper diagnosis [15]. Preliminary diagnosis - established by a specialist in toxicology, intensive care or anesthesiology - requires confirmation by laboratory tests; to the ability to achieve it. It is crucial to know the statistics of poisonings that currently tend to be most common in the local population - as toxicological laboratory analyses are often significantly accelerated when any information is available on the chemical compound group the xenobiotic in question can possibly belong to [16].

\section{Materials AND Methods}

Data on hospital admissions secondary to poisonings by nonopioid analgesics, antipyretics and antirheumatics (T39-T39.9 according to ICD-10) in the years 2006-2012, made available due to courtesy of the public healthcare insurance provider Narodowy Fundusz Zdrowia in Lower Silesia region of Poland (NFZ), were analyzed; the data included all admissions to hospital regardless of the subsequent hospital stay duration length. The statistical analyses were carried out using the Microsoft Office Excel 2007 software. The aim of the study was to find out the current incidence and trends in the most common and important poisonings by nonopioid analgesics, antipyretics and antirheumatics in the analyzed period of time to facilitate the process of diagnostics both clinical and forensic medicine purposes. The structure of data the authors were given access to by courtesy of the NFZ did not allow performing analyses of any correlations between poisoning and other important factors characterizing the intoxicated patients - like age, gender or socioeconomic conditions.

\section{RESULTS AND DISCUSSION}

The Lower Silesia region of Poland population's crucial characteristics, including its amount or age structure, did not change in the years 2006-2012 although ageing effects were marked [17]. The Lower Silesia region, according to the year 2014 data, was inhabited by 2,9 million people, males comprising $48 \%$ of the total number [18]. The study revealed that in the analyzed period there were total 2488 cases of hospital admissions recorded as caused by poisoning by nonopioid analgesics, antipyretics and antirheumatics (T39-T39.9 according to ICD-10).

The reported to the NFZ yearly amount of admissions to hospitals in the Lower Silesia region of Poland in the years 2006-2012 due to poisoning by nonopioid analgesics, antipyretics and antirheumatics, that were not specified further (T39 according to ICD-10) increased within the analyzed period and in the year 2012 it reached $205,7 \%$ of the initial value - as it is visible in Figure 1; the total amount of the recorded cases in the analyzed period was 680 . This increase needs be interpreted in the context of both rising expenses on drugs in the Polish society and growing popularity of the OTC drugs, which lead to their wide availability and thus also causes the increased risk of accidental or intentional overdose. 
Analysis of Dynamics in Hospital Admissions Due to Poisonings by Nonopioid Analgesics, Antipyretics and Antirheumatics (T39 ICD-10) in Lower Silesia Region of Poland in Years 2006-2012

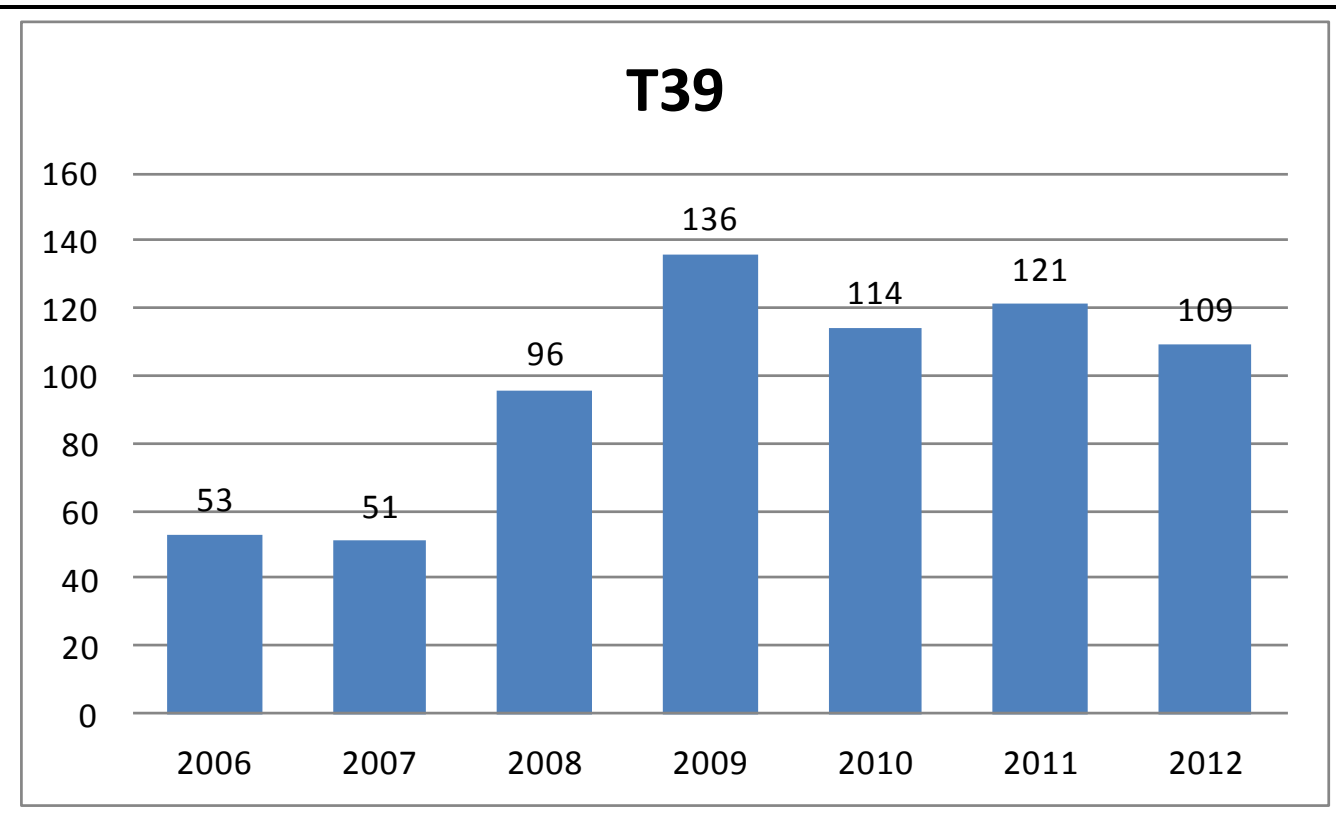

Figure1. Yearly amounts of admissions to hospitals in the Lower Silesia region of Poland in the years 20062012 due to poisoning by nonopioid analgesics, antipyretics and antirheumatics (T39 according to ICD-10) not specified further; source: data made available by courtesy of the NFZ.

Salicylate poisonings (T39.0 according to ICD-10) were not very common, with the total amount of 194 cases in the years 2006-2012. In the significant part of the analyzed period the yearly amount of this group of hospital admissions demonstrated dropping trend and in the year 2012 it was limited to $77,8 \%$ of the initial value - as it is presented in Figure 2. The popularity of salicylates among patients gets undermined by newer generations of drugs that cause less burdensome side effects in every-day life and less frequent use of these drugs might in turn limit the risk of overdose.

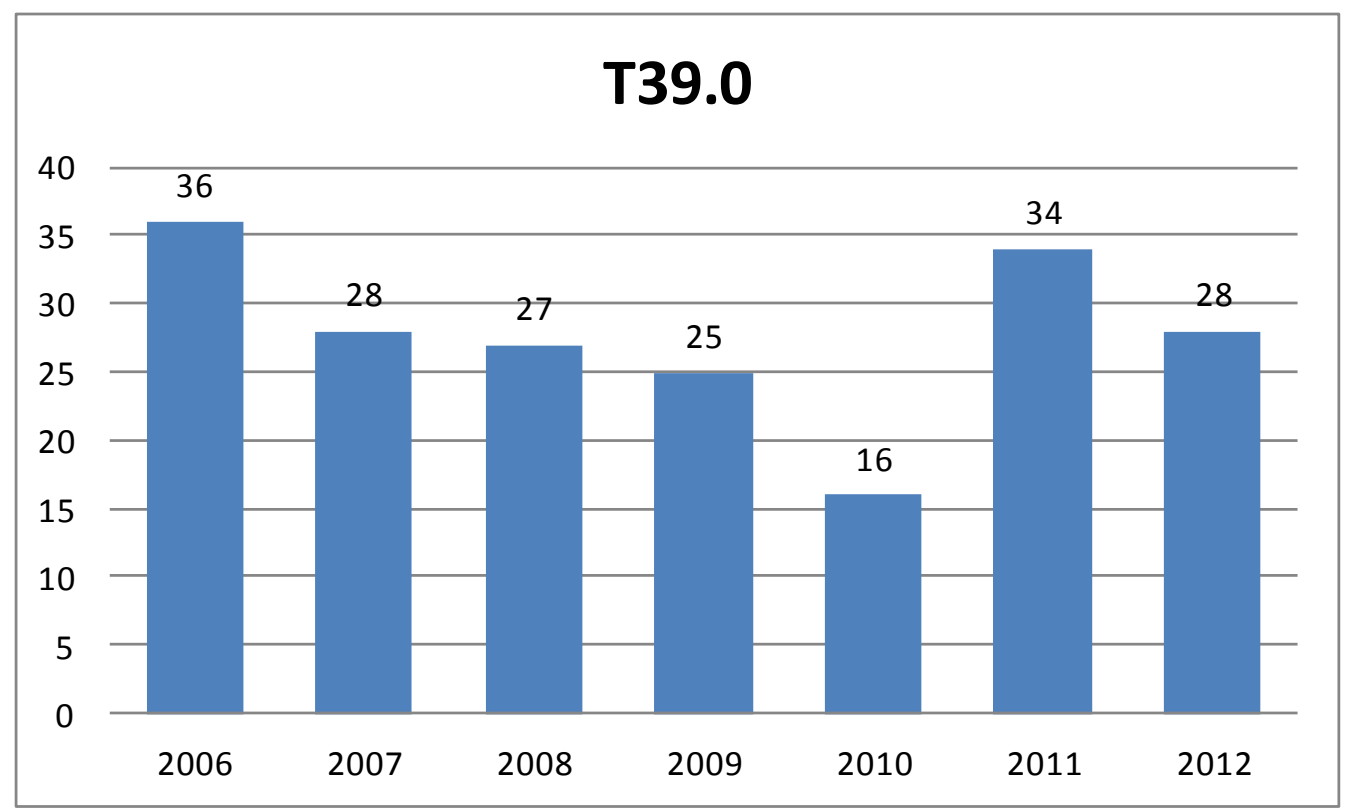

Figure2. Yearly amounts of admissions to hospitals in the Lower Silesia region of Poland in the years 20062012 due to poisoning by salicylates (T39.0 according to ICD-10); source: data made available by courtesy of the NFZ.

The total amount of reported poisonings by 4-aminophenol derivates (T39.1 according to ICD-10) that required hospitalization in the whole analyzed period was 310; the yearly amount of hospital admissions increased in the years 2006-2012 to $141,9 \%$ of the initial value - as it is shown in Figure 3. This increase shall be interpreted in connection with the phenomenon of rising expenses on drugs in Poland and the aggressive media advertising strategies promoting this group of OTC medications. 


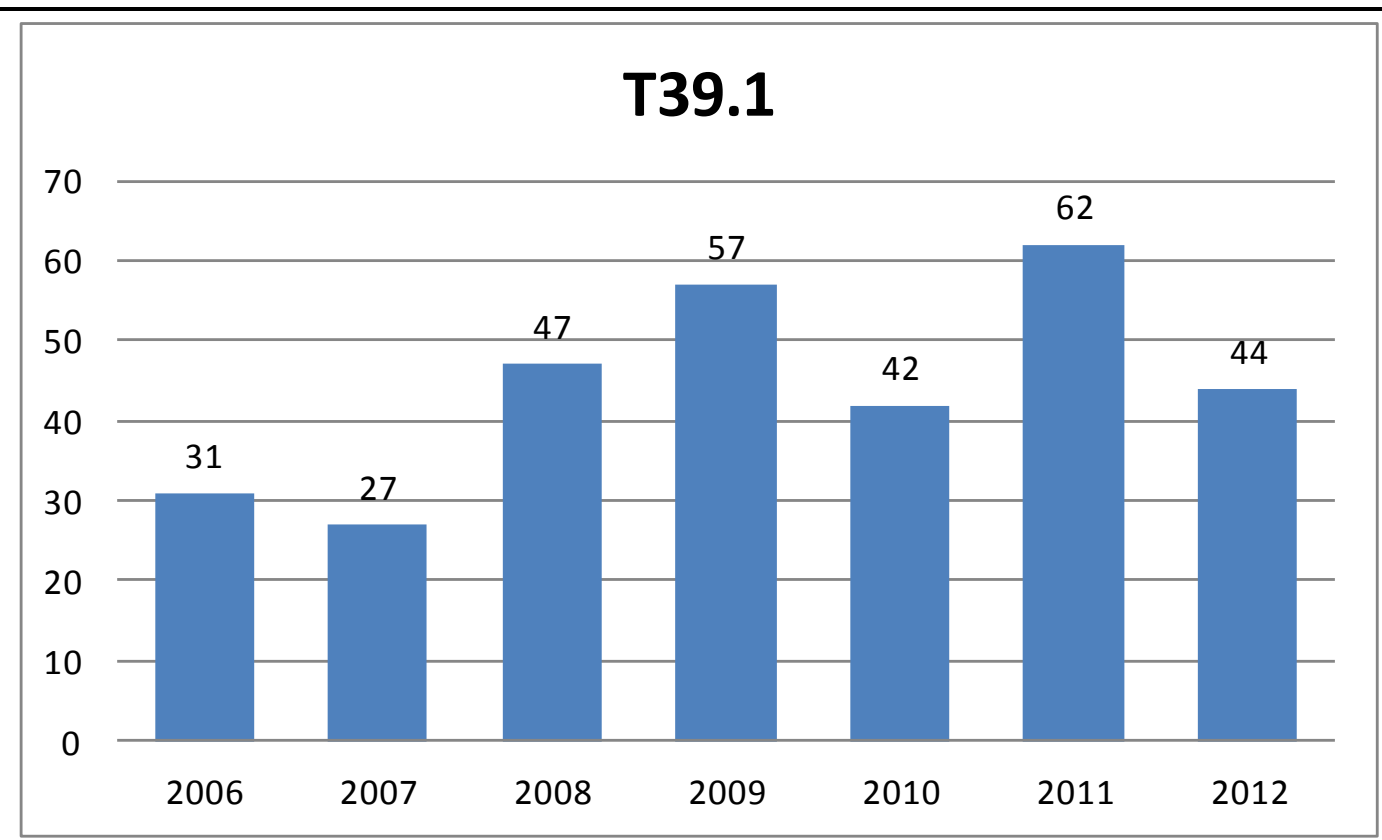

Figure3. Yearly amounts of admissions to hospitals in the Lower Silesia region of Poland in the years 20062012 due to poisoning by 4-aminophenol derivates (T39.1 according to ICD-10); source: data made available by courtesy of the NFZ.

Intoxications with pyrazolone derivates (T39.2 according to ICD0-10) were casuistic in the Lower Silesia region of Poland in the analyzed period, with the total amount of 7 -as it is visualized in Figure 4.

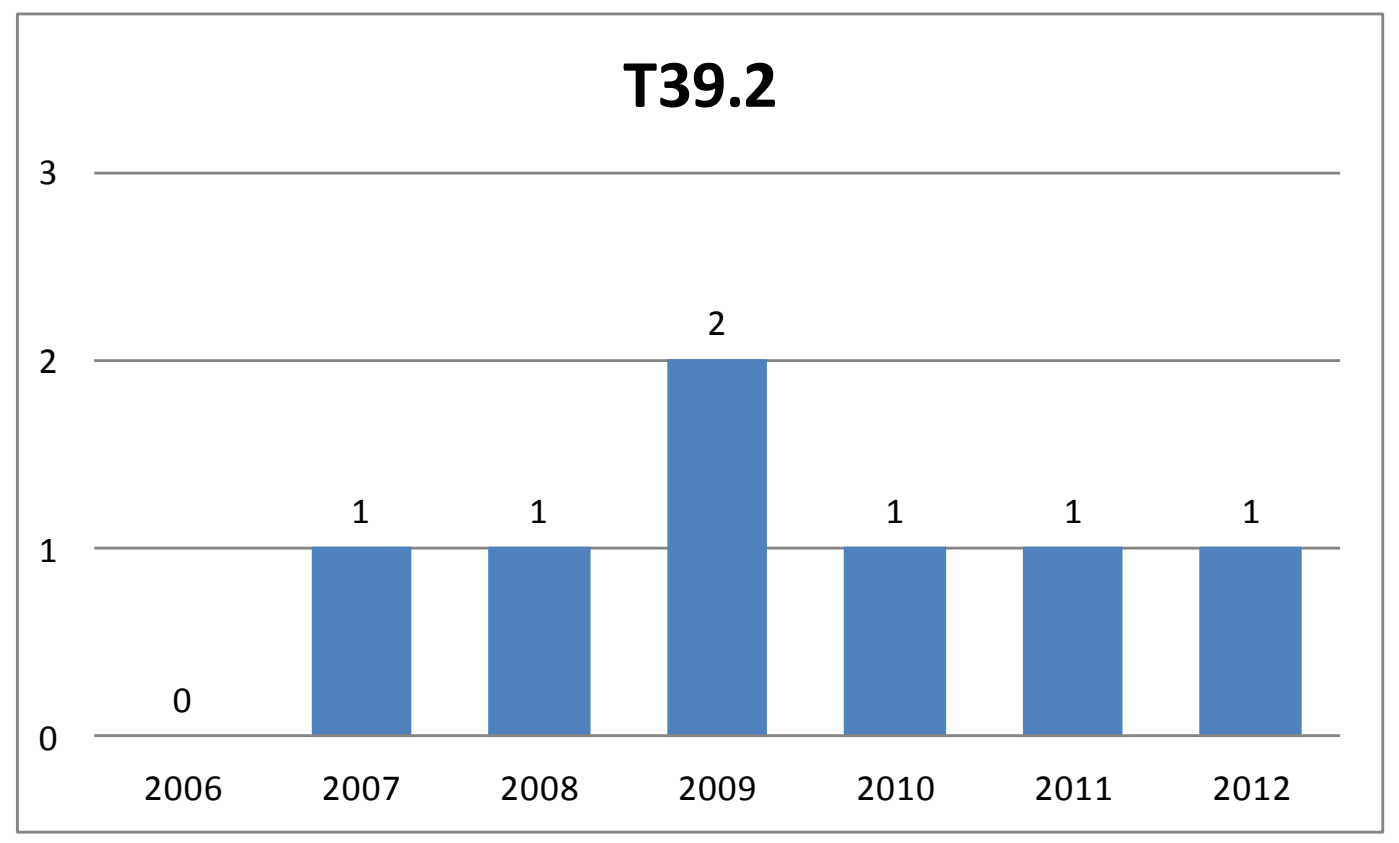

Figure4. Yearly amounts of admissions to hospitals in the Lower Silesia region of Poland in the years 20062012 due to poisoning by pyrazolone derivates (T39.2 according to ICD-10); source: data made available by courtesy of the NFZ.

The total amount of hospital admissions due to poisoning by nonsteroidal anti-inflammatory drugs (NSAID) other than salicylates, 4-aminophenol derivates or pyrazolone derivates (T39.3 according to ICD-10) was 772 in the whole analyzed period; the yearly amount of such hospitalizations rose significantly starting from the year 2008 so in the year 2012 it reached $225 \%$ of the initial value - as it is presented in Figure 5. This increase shall be considered in the common context with the rise in spending on drugs by an average Pole and with the patient-friendly image of those drugs created by the media in Poland. 
Analysis of Dynamics in Hospital Admissions Due to Poisonings by Nonopioid Analgesics, Antipyretics and Antirheumatics (T39 ICD-10) in Lower Silesia Region of Poland in Years 2006-2012

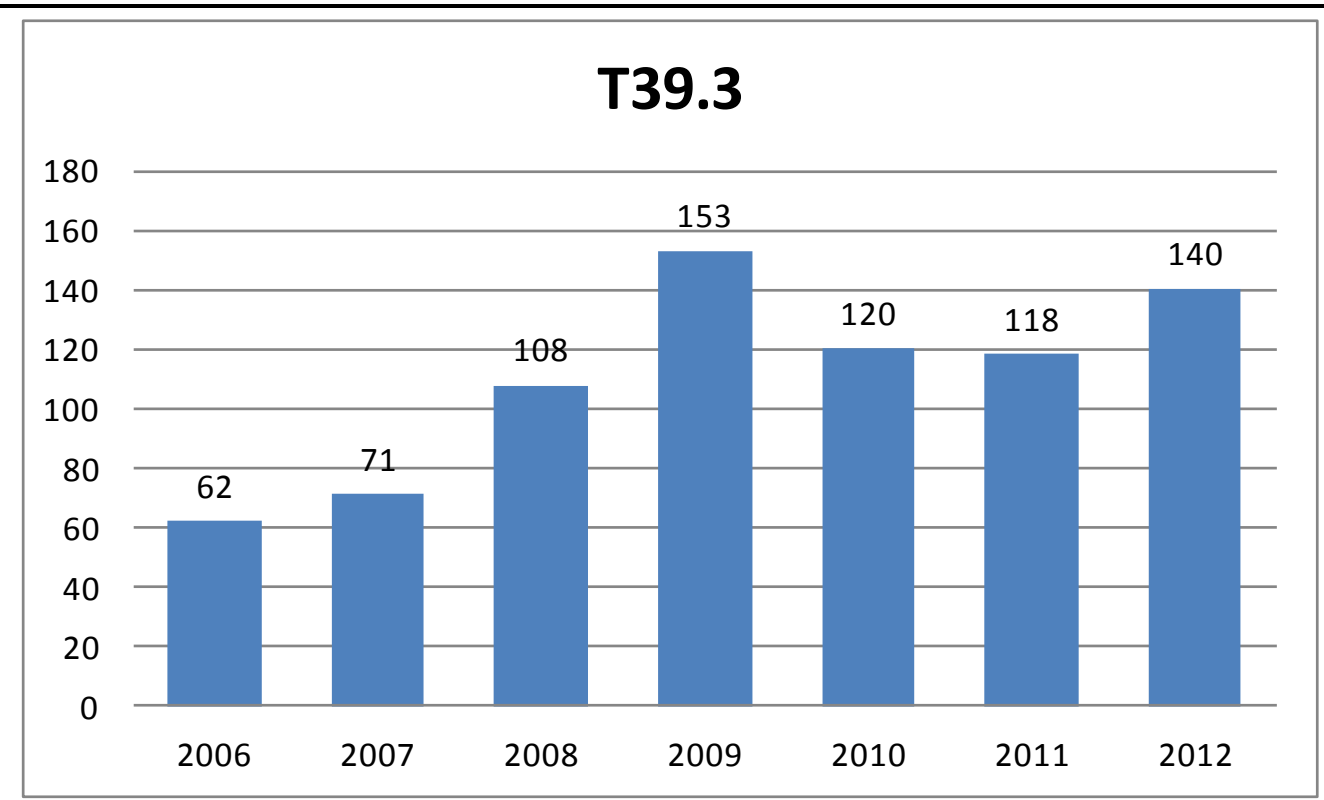

Figure5. Yearly amounts of admissions to hospitals in the Lower Silesia region of Poland in the years 20062012 due to poisoning by nonsteroidal anti-inflammatory drugs (NSAID) other than salicylates, 4-aminophenol derivates or pyrazolone derivates (T39.3 according to ICD-10); source: data made available by courtesy of the NFZ.

Cases of poisoning by antirheumatics, with exception of glucocorticoids and salicylates (T39.4 according to ICD-10) were very rare in the Lower Silesia region of Poland in the analyzed period, with the total amount of 23 - as it is illustrated in Figure 6. It can be associated with the fact, that those drugs are not intensively advertised in the media and their recognition in the vast public is minimal; their availability to the average person is limited as they are dispensed on the basis of physicians' prescriptions.

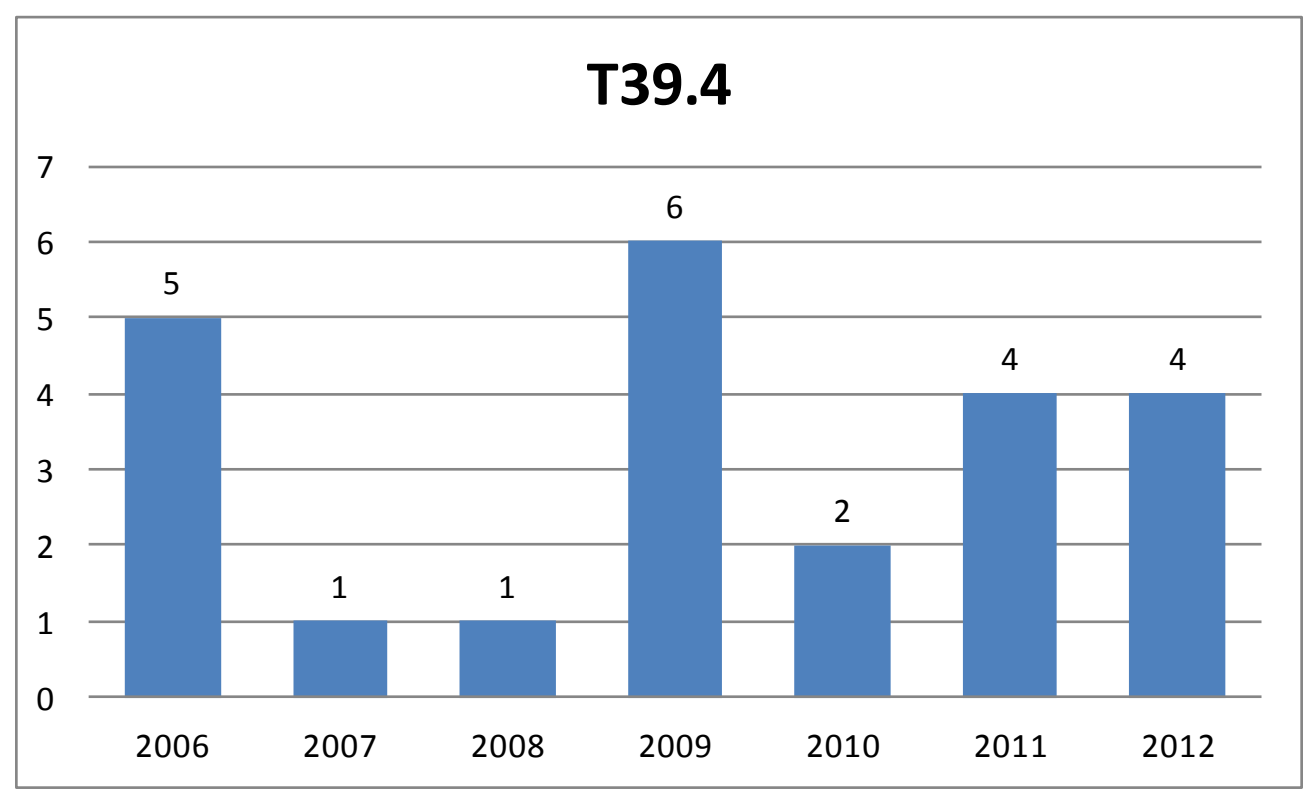

Figure6. Yearly amounts of admissions to hospitals in the Lower Silesia region of Poland in the years 20062012 due to poisoning by antirheumatics not classified elsewhere, with the exception of glucocorticoids and salicylates (T39.4 according to ICD-10); source: data made available by courtesy of the NFZ.

Yearly amounts of admissions to hospitals in the Lower Silesia region of Poland in the years 20062012 due to poisoning by nonopioid analgesics and antipyretics not classified elsewhere, other than salicylates, 4-amionophenol derivates, pyrazolone derivates, other nonsteroidal antiinflammatory drugs and antirheumatics (T39.8 according to ICD-10) were alternating, although with marked rising trend - as it is shown in Figure 7. The total amount of hospitalizations in this group in the years 2006-2012 reached 223. 


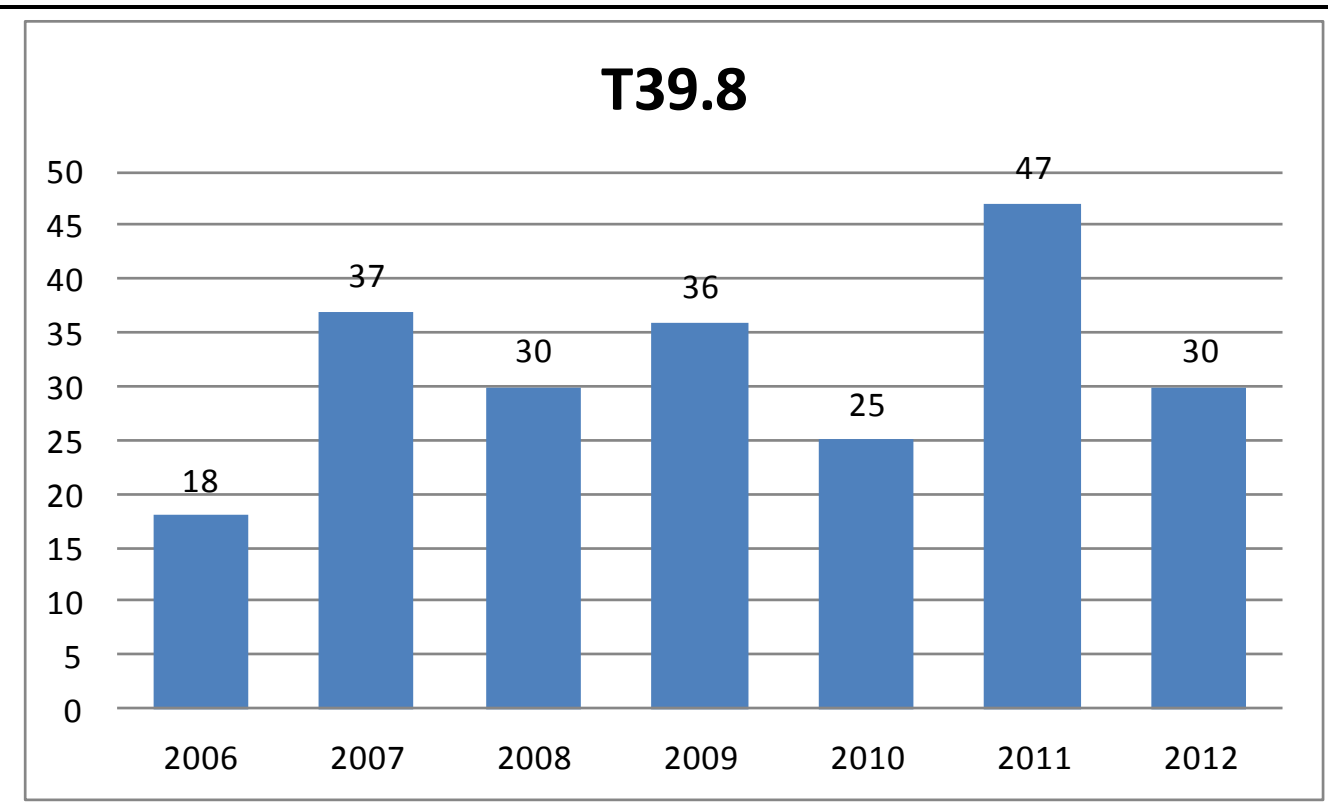

Figure7. Yearly amounts of admissions to hospitals in the Lower Silesia region of Poland in the years 20062012 due to poisoning by nonopioid analgesics and antipyretics not classified elsewhere, other than salicylates, 4-amionophenol derivates, pyrazolone derivates, other nonsteroidal anti-inflammatory drugs and antirheumatics (T39.8 according to ICD-10); source: data made available by courtesy of the NFZ.

Unspecified nonopioid analgesics, antipyretics and antirheumatics poisoning cases (T39.9 according to ICD-10) requiring hospitalization were reported in the Lower Silesia region of Poland in the analyzed years at a yearly rate that was close to constant; the total amount of cases in the years 2006-2012 was 279 - as it is visualized in Figure 8.

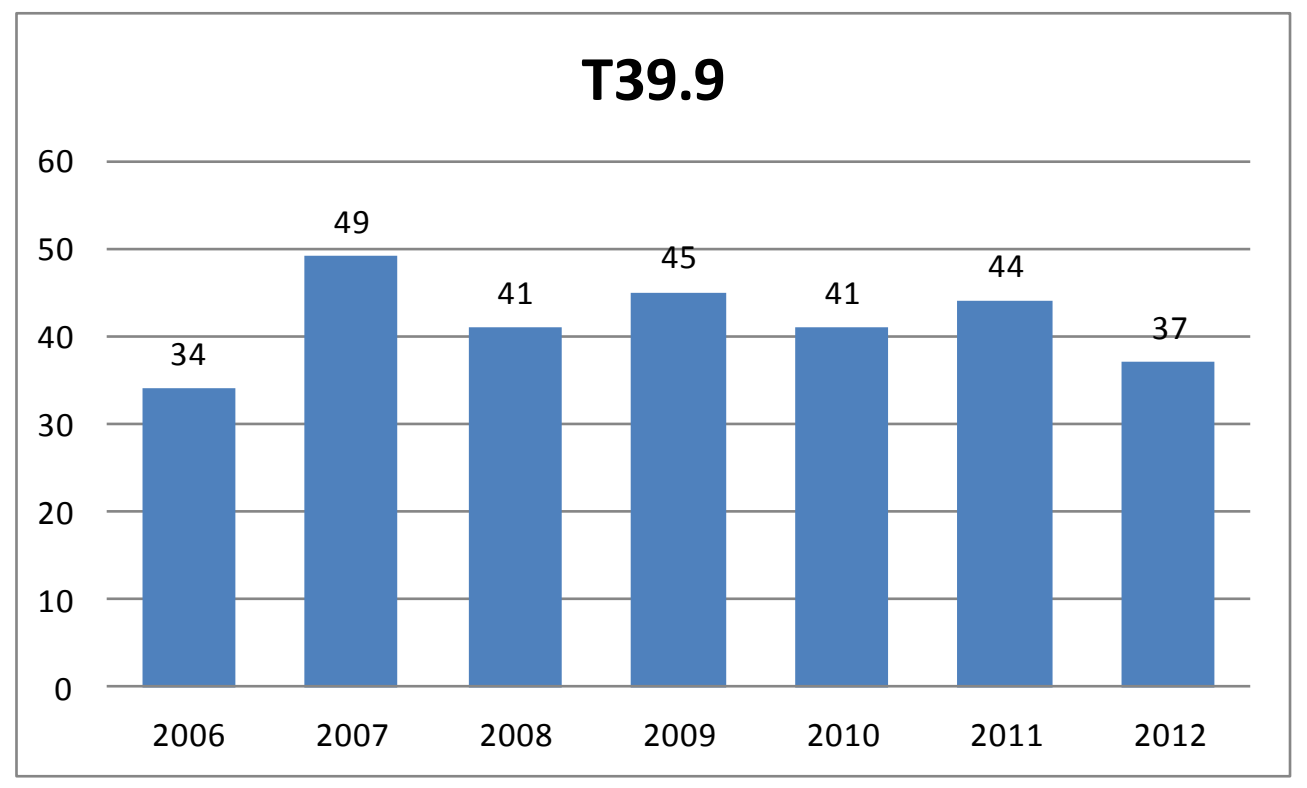

Figure8. Yearly amounts of admissions to hospitals in the Lower Silesia region of Poland in the years 20062012 due to poisoning by unspecified nonopioid analgesics, antipyretics and antirheumatics (T39.9 according to ICD-10); source: data made available by courtesy of the NFZ.

The statistical structure of reported poisoning cases in the Lower Silesia region of Poland in the years 2006 and 2012 is summed up in Figure 9. It is visible that the major problem is poisoning by nonsteroidal anti-inflammatory drugs (NSAID) other than salicylates, 4-aminophenol derivates or pyrazolone derivates (T39.3 according to ICD-10), which most probably are still underreported and in significant amount of cases they were registered as: poisonings by nonopioid analgesics, antipyretics and antirheumatics not specified further or unspecified at all (T39 and T39.9 according to ICD-10, respectively). In comparison to data from the year 2006, in the year 2012 there was also a significant increase in the amount of these poisoning cases, as well as a rise of hospital admissions related to poisoning by 4 -aminophenol derivates (T39.1 according to ICD-10). 
Analysis of Dynamics in Hospital Admissions Due to Poisonings by Nonopioid Analgesics, Antipyretics and Antirheumatics (T39 ICD-10) in Lower Silesia Region of Poland in Years 2006-2012

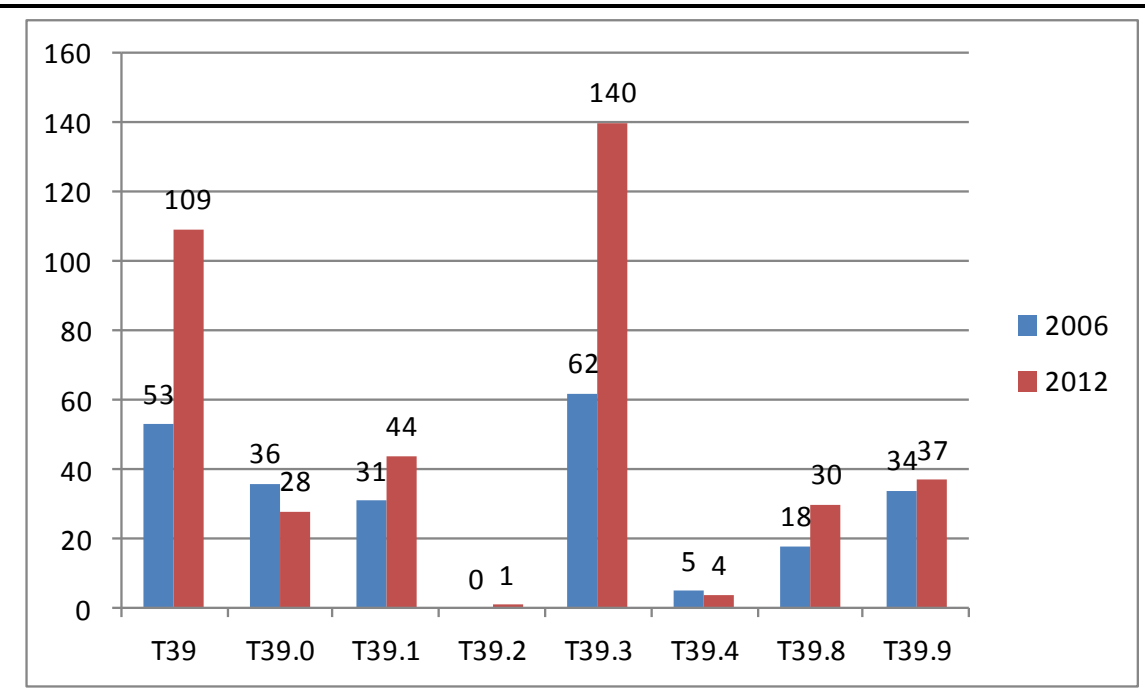

Figure9. Yearly amounts of admissions to hospitals in the Lower Silesia region of Poland in the years 20062012 due to poisoning by nonopioid analgesics, antipyretics and antirheumatics (T39-T39.9 according to ICD10); source: data made available by courtesy of the NFZ.

\section{Conclusion}

Cases of poisoning by nonopioid analgesics, antipyretics and antirheumatics needing hospital admission were not very common in the Lower Silesia region of Poland in the years 2006-2012 but they demonstrated a rising trend - it included both cases reported as confirmed poisonings by 4aminophenol derivates and nonsteroideal anti-inflammatory drugs (NSAID) and cases without any further specification (T39.1, T39.3 and T39 according to ICD-10, respectively). Under current Polish legal regulations, the vast majority of these drugs are sold as OTC medications and are very commonly used in self-medication as painkillers and antipyretics; they are advertised as safe and marketed practically everywhere at cheap prices, thus they are easily available to anyone: in practically unlimited amounts and under different product names. As it causes both elevated unintentional overdose risk and growing popularity of those drugs as tools in self-harm attempts a possible intoxication with those drugs shall be seriously considered in differential diagnosis by every physician, including intensive care and anesthesiology medical staff. In contrast, the amount of serious poisonings by drugs not popularized by media - including salicylates, pyrazolone derivates and antirheumatics (T39.0, T39.2 and T39.4 according to ICD-10, respectively) - was low or demonstrated a dropping trend in the Lower Silesia region of Poland in the analyzed years; those drugs are not the first-line options in the differential diagnosis of intoxications anymore.

The significant - and not changing in the analyzed years - amount of cases that were reported as poisonings by unspecified nonopioid analgesics, antipyretics and antirheumatics (T39.9 according to ICD-10) confirms the fact that fast and exact identification of unknown xenobiotics in case of acute intoxication can still cause problems, even considering the availability of current high-tech analytic methods.

\section{ACKNOWLEDGMENTS}

The authors thank the NFZ for allowing them the access to the publication-relevant data.

\section{REFERENCES}

[1] Bochenek T, Godman B, Lipowska K, Mikrut K, Zuziak S, Pedzisz M, Nowak A, Pilc A, Overthe-counter medicine and dietary supplement consumption among academic youth in Poland, Expert Review of Pharmacoeconomics \& Outcomes Research, 2016, Vol 16, Issue 2, PP 199205 DOI: http://dx.doi.org/10.1586/14737167.2016.1154790

[2] Wojta-Kempa M, Krzyzanowski D, Correlates of abusing and misusing over-the-counter pain relievers among adult population of Wroclaw, Poland, Adv Clin Exp Med, 2016, Vol 25, Issue 2, PP 349-360 http://www.advances.umed.wroc.pl/en/article/2016/25/2/349/ [accessed: 2016.07.28]

[3] Szpringer M, Oledzka M, Kosecka J, Sobczyk B, Grabowska P, Use of the over-the-counter drugs by adults and an assessment of the impact of advertisements on consumers, Studia Medyczne, 2015, Vol 31, Issue 1, PP 42-47 DOI: http://dx.doi.org/10.5114/ms.2015.49951 
[4] Turek A, Owczarek A, Derterminants of consumption behavior of over-the-counter medications - the case of painkillers and anti-inflammatroy medications, Journal of Economics \& Management,2014,Vol 15, PP 25-59 http://www.ue.katowice.pl/fileadmin/_migrated/ content _uploads/2_Turek_Owczarek_Determinants_of_Consumption....pdf [accessed: 2016.07.28]

[5] Czerw A, Religioni U, Grom K, Augustynowicz A, The impact of television advertising of medical products on OTC painkillers purchase in Poland, Medical and Biological Sciences, 2015, Issue 29, Vol 4, PP 23-28 DOI: http://dx.doi.org/10.12775/MBS.2015.030

[6] Czerw A, Marek E, Restrictions on the conduct of advertising of medicinal products in Poland and their violations, Acta Poloniae Pharmaceutica - Drug Research, 2013, Vol 70, No 4, PP 769776 http://www.ptfarm.pl/pub/File/Acta_Poloniae/2013/4/769.pdf [accessed: 2016.07.28]

[7] Dobrogowski J, Wordliczek J, Szczudlik A, Stepien A, Drobnik J, Leppert W, Krajnik M, Woron J, Zajaczkowska R, Kocot-Kepska M, Przeklasa-Muszynska A, Jakowicka-Wordliczek j, Kollataj M, Janecki M, Pyszkowska J, Boczar K, Suchorzewski M, Mordarski S, Suslo R, Malec-Milewska M, Long-Term Strong Opioid Use in Noncancer Pain: A Review of the Literature and Recommendation of the Polish Association for the Study of Pain, Polish Neurological Society and Polish Society of Family Medicine, Bol, 2015, Vol 16, Issue 3, PP 929 DOI: http://dx.doi.org/10.5604/1640324x.1178726

[8] Drobnik J, Trnka J, Suslo R, Steciwko A, The new category of the medical error - the inquiry error, Family Medicine \& Primary Care Review, 2009, Vol 11, Issue 3, PP 593-594 http://www.familymedreview.org/files/2009/pdf_032009/5_reviews_577_803.pdf [accessed: 2016.07.28]

[9] Drobnik J, Suslo R, Trnka J, Kordel K, The importance of the proper provision of information to patients about medicines in the context of the risks in road traffic and workplace, Family Medicine \& Primary Care Review, 2011, Vol 13, Issue 2, PP 302-304 http://www.familymedreview.org/files/2011/pdf_022011/4_reviews_281_355.pdf [acceessed: 2016.07.28]

[10] Bazydlo M, Zultak-Baczkowska K., Zaremba-Pechmann L, Rotter I, Karakiewicz B., Analysis of the OTC treatment without consultation in different age groups and evaluation of need for health education, Family Medicine \& Primary Care Review, 2010, Vol 12, Issue 2, PP 127 130 http://www.familymedreview.org/files/2010/pdf_022010/2_original_papers_127_312.pdf [accessed:2016.07.28]

[11] Wroblewski T., Kobryn K, Koziel S, Oldakowska-Jedynak U, Pinkas J, Danielewicz R, Ziarkiewicz-Wroblewska B, Krawczyk M, Acetaminophen (Paracetamol) induced acute liver failure - a social problem in an era of increasing tendency to self-treatment, Ann Agric Environ Med, 2015, Vol 22, Issue 4, PP 762-767 DOI: http://dx.doi.org/10.5604/12321966.1185790

[12] Kominek K, Pawłowska-Kamieniak A, Mroczkowska-Juchkiewicz A, Krawiec P, PacKozuchowska E, Intentional and accidental paracetamol poisoning in childhood - a retrospective analysis, Postepy Hig Med Dosw, 2015, Issue 69, PP 452-456 http://www.phmd.p1/ fulltxt.php? ICID $=1148745$ [accessed: 2016.07.28]

[13] Khandelwal N, James L, Sanders C, Larson A, Lee W, Acute Liver Failure Study Group: Unrecognized acetaminophen toxicity as a cause of 'indeterminate' acute liver failure, Hepatology, 2011; Vol 53, PP 567-576 DOI: http://dx.doi.org/10.1002/hep.24060

[14] Suslo R, Drobnik J, Trnka J, Rozpoznawanie i dokumentowanie przypadkow przewleklej intoksykacji wsrod pacjentow podstawowej opieki zdrowotnej, Przew Lek, 2010, Vol 13, Issue 2, PP 180-183 http://www.termedia.pl/Rozpoznawanie-i-dokumentowanie-przypadkowprzewleklej-intoksykacji-wsrod-pacjentow-podstawowej-opieki-zdrowotnej,8,14379,0,0.html [accessed: 2016.07.28]

[15] Suslo R, Trnka J, Filinowicz M, Drobnik J, Zatrucia lekami in: Medycyna rodzinna - co nowego? T.2, red: Steciwko A, Wroclaw, Cornetis 2010, PP 237-240

[16] Imran M, Screening for unknown compounds in Forensic Toxicology, ARC Journal of Forensic Science, 2016, Vol 1, Issue 1, PP 10-12 DOI: http://dx.doi.org/10.20431/2456-0049.0101002

[17] Drobnik J, Suslo R, Kurpas D, Trnka J.: Analysis of elderly people care system and their health needs in the Lower Silesia region; Fam.Med.Prim.Care Rev., 2010, Vol 12, Issue 2; PP 165-167 http://www.familymedreview.org/files/2010/pdf_022010/2_original_papers_127_312.pdf [accessed: 2016.07.28]

[18] Central Statistical Office of Poland Information Portal http://stat.gov.pl/statystykaregionalna/rankingi-statystyczne/ludnosc-wedlug-wojewodztw/ [accessed: 2016.07.28] 